\title{
Un cambio en la ratio fidei. Asociación (aparentemente ilícita) entre principios teológicos y datos empíricos
}

\author{
Carlos Schickendantz \\ CENTRO TEOLÓGICO MANUEL LARRAÍN \\ UNIVERSIDAD ALBERTO HURTADO \\ cschickend@uahurtado.cl
}

Resumen: Se advierte todavía hoy una cierta perplejidad para describir la noción 'signos de los tiempos', determinar su criteriología y, especialmente, situar con exactitud su lugar en el proceso de comprensión y argumentación teológica. El texto refiere en particular a la elaboración de un autor significativo -P. Hünermann- que propone la consideración de los signos de los tiempos como un momento esencial para una teología acorde a los desafíos de la época. Algunas preguntas guían el trabajo: ¿Cuál es el punto de partida que conduce a esta consideración? ¿Qué argumentos y cuáles autores entran en juego? ¿Cómo se relaciona esta perspectiva con el Vaticano II? ¿Cómo se caracterizan los signos de los tiempos? El texto concluye con una hipótesis que permita conceptualizar el cambio en la metodología teológica impulsado en Gaudium et spes.

Palabras clave: Signos de los tiempos, lugar teológico, método teológico

Abstract: There is still some perplexity to describe the notion of 'signs of the times', determine its criteriology, and locate its place in the process of understanding and theological argumentation. The text refers in particular to the development of a significant author-P. Hünermann- who proposes the consideration of the signs of the times as an essential moment for a theology according to the challenges of our time. Some questions guide the work: What is the starting point that leads to this consideration? What arguments and which authors come into play? How is this perspective related to Vatican II? How are the signs of the times characterized? The text concludes with a hypothesis that allows to conceptualize the change in theological methodology promoted in Gaudium et Spes.

Keywords: Signs of the times, theological place, theological method 
En la bibliografía internacional sobre el tema 'signos de los tiempos' se advierte todavía hoy, incluso en autores calificados, una cierta perplejidad para describir dicha noción, determinar su criteriología y, particularmente, situar con exactitud su lugar en el proceso de comprensión y argumentación teológica ${ }^{1}$. Un ejemplo reciente es iluminador. Richard Hartmann narra que para la reunión anual de teólogos y teólogas pastoralistas de lengua alemana de 2014 en Salzburgo les solicitaron a cuatro colegas que, según sus diversas disciplinas y perspectivas, identificaran algunos signos de los tiempos y que fundamentaran sus propuestas. Hartmann advierte que las respuestas fueron "demasiado diversas"; a partir de ellas resultaba imposible elaborar una "criteriología" con consenso. El diálogo entre todos los asistentes permitió canalizar el asunto, pero, reconoce, defraudó las expectativas de poder regresar a casa con un concepto operativo claro. Para encontrar una respuesta satisfactoria el único camino posible parece ser el de realizar una observación sobre la manera como diversos autores diferencian y valoran los signos de los tiempos. Al revisar su contribución y prestar atención a las diversas perspectivas expuestas, Hartmann advierte que las insuficiencias se multiplican: por una parte, refiere a una "doble inseguridad", en orden a la identificación de los signos y en relación a lo que significa interpretarlos a la luz del Evangelio; por otra, constata también, luego de analizar varios textos bíblicos, que esa búsqueda no conduce a un resultado que exprese con claridad el significado del concepto ${ }^{2}$.

El diagnóstico de Hartmann, aunque breve, es sintomático. Efectivamente, si en la bibliografía teológica más amplia se advierte un uso muy difundido y genérico del concepto, son significativas las limitaciones que autores de relieve, que incluso han trabajado particularmente la categoría y que de algún modo la interpretan como esencial para el trabajo teológico actual, no dejan de expresar y repetir. P. Hünermann constata, por una parte, las dificultades existentes en la "determinación

1 Este texto se enmarca en el proyecto de investigación Fondecyt $\mathrm{N}^{\circ} 1150128$, cuyas líneas generales se explicitan en C. Schickendantz, "Autoridad teológica de los acontecimientos históricos. Perplejidades sobre un lugar teológico", en Teología 115 (2014) 157-183. Cf. https://uahurtado.academia.edu/CarlosSchickendantz

2 Cf. R. Hartmann, "'Zeichen der Zeit" - Relevanz für das Selbstverständnis einer synodalen Kirche”, en J. Schmiedl (ed.), Die Kirchenbilder der Synoden. Zur Umsetzung konziliarer Ekeklesiologie in teilkirchlichen Strukturen (Herder, Freiburg i.Br. 2015) 251 $271,255,254,260$ respectivamente. 
conceptual" de esta idea, el hecho de que no se ha alcanzado un consenso en tal tarea y, por otra, que "hasta ahora no han sido elaborados criterios claros y universalmente válidos para la determinación de los signos de los tiempos". Existen, reconoce el autor, numerosas áreas de coincidencia, pero es necesaria una profundización y, en particular, la elaboración de una criteriología ${ }^{3}$. En un texto de 2012 argumenta que algunas de las dificultades con esta categoría no son superficiales. En buena medida tienen que ver con el problema estructural de la Constitución Pastoral: "no se veía cómo podían conjugarse afirmaciones histórico-contingentes y afirmaciones de principios". ¿Desarrolla Gaudium et spes la ratio fidei o la ratio mundi buius? Estas dudas, expresa el teólogo alemán, se manifiestan en la interpretación "discutida hasta el día de hoy, de aquello a lo que propiamente se apunta con la expresión 'signos de los tiempos". Bajo esta "asociación en apariencia metodológicamente ilícita entre principios y datos empíricos", está en cuestión la "forma histórica de pensar". . Otros autores hablan, en referencia también a la insuficiencia de Gaudium et spes y al desarrollo posterior, sobre la carencia de un "instrumento metodológico de una teología del presente"

Una opinión relevante sobre el estado de la cuestión, indudablemente, es la de W. Kasper. Reconoce que Gaudium et spes representó una "nueva orientación" en la relación Iglesia-mundo que se prestó a perplejidades. La cuestión, a su juicio, reside en determinar qué significa desde el punto de vista normativo el estar "en el mundo", realidad indiscutible desde lo puramente empírico y fenomenológico. Por una parte, Kasper se interroga acerca de la autoridad de la misma Constitución pastoral;

3 Cf. P. Hünermann, "El trabajo teológico al comienzo del tercer milenio. Los signos de los tiempos como elementos esenciales de una teología histórica", en P. Hünermann, El Vaticano II como software de la Iglesia actual (Ed. Universidad Alberto Hurtado, Santiago 2014) 217-261, 242.

4 P. Hünermann, "Perplejidad del lenguaje ante el Concilio Vaticano II?", en Concilium 346 (2012) 319-333, 323, 333, 330 respectivamente. H.-J. SANDER representa un esfuerzo significativo por evitar el "paralelismo entre la realidad de Dios y la realidad del tiempo". Cf. "Das singuläre Geschichtshandeln Gottes- eine Frage der pluralen Topologie der Zeichen der Zeit", en B.-J. Hilberath - P. HünermanN (ed.), Herders Theologischer Kommentar zum Zweiten Vatikanischen Konzil. 5 Theologische Zusammenschau und Perspektiven (Herder, Freiburg i.Br. 2006) 134-147, 138.

5 R. Polak - M. Jäggle, "Gegenwart als locus theologicus", en J.-H. Tück (ed.), Erinnerung an die Zukunft. Das Zweite Vatikanische Konzil (Herder, Freiburg i.B. 2012) 570-598, 573. 
representa "un problema de metodología teológica fundamental". Por otra, recuerda que el Concilio habla de signos de los tiempos, pero se pregunta "cómo se determinan" dichos signos y "cómo se determina más precisamente su relación con los principios teológicos". En una cita repite con palabras análogas el interrogante apuntado: "Permanece sin aclarar cómo se determinan y ordenan metodológica y teológicamente los signos de los tiempos" ". A su juicio, hasta el día de hoy difieren las opiniones de los diversos autores sobre las cuestiones no aclaradas en la Constitución pastoral.

Como se deduce con claridad de estas opiniones -y de otras semejantes que podrían incluirse- en las perplejidades referidas a la categoría pastoral signos de los tiempos se problematizan asuntos de fondo: la cuestión acerca de la metodología teológica, estrechamente vinculada al peculiar documento conciliar Gaudium et spes y como expresión de un progreso histórico-dogmático en la ciencia teológica en buena medida debido a la asunción de la conciencia de la historicidad, que dicha categoría simbólica visibiliza. El asunto se aprecia bien en la formulación citada: una "asociación en apariencia metodológicamente ilícita entre principios y datos empíricos".

En el marco de la teología europea P. Hünermann destaca -junto a otros que poseen expresiones análogas, como C. Theobald, G. Ruggieri y H.-J Sander- por su propuesta de considerar los signos de los tiempos "como elementos esenciales de una teología histórica" en el marco de una descripción sobre las características que debe poseer un trabajo adecuado "al comienzo del tercer milenio"7. Es mi opinión que una atención detenida a diversos trabajos de Hünermann contribuiría, si no a resolver las cuestiones abiertas, sí a encaminar el tratamiento del asunto en una forma teológicamente consistente y plausible. Sobre la base de las reflexiones de Hünermann propongo, particularmente al final, unos pasos ulteriores para hacer frente a la cuestión abierta formulada por Kasper en estas palabras: "cómo se ordenan metodológica y teológicamente los signos de los tiempos", "cómo se determina más precisamente su relación con los principios teológicos". El tratamiento más detenido de un autor europeo no significa minusvalorar la tradición

${ }^{6} \quad$ Katholische Kirche. Wesen - Wirklichkeit - Sendung (Herder, Freiburg i.Br. 2011) 454, 567 nota 133.

7 Cf. "El trabajo teológico al comienzo del tercer milenio", 217. 
eclesial y teológica que -bajo la forma del método ver-juzgar-actuareste tipo de pensamiento tiene en América latina ${ }^{8}$. Por el contrario, el aporte está puesto al servicio de afinar la conciencia metodológica en un asunto relevante para los procesos de inculturación en sociedades plurales, en una aldea global y una iglesia mundial.

\section{LA IRRUPCIÓN DEL PENSAMIENTO HISTÓRICO COMO PUNTO DE PARTIDA}

Los análisis de Hünermann tienen que ver con ideas que se remontan a sus años de formación intelectual, en concreto, a la temática de su tesis de habilitación para la docencia universitaria acerca de la "irrupción del pensamiento histórico en el siglo XIX” y su significado para la teología. En el estudio de importantes autores de la llamada Escuela de Tubinga destacaba en 1967 este aspecto precisamente: "La fisonomía de nuestra época está impregnada por un nuevo desarrollo del sentido histórico". Se trata de "la constitución histórica de la realidad en su conjunto". Ese "descubrimiento de la historia y la historicidad" le parece, con la cita de algunos autores, "una de las más grandes revoluciones espirituales que ha vivido el pensamiento occidental"'. Alude al proceso que tiene en Wilhelm Dilthey un autor emblemático y que se extiende y desarrolla con múltiples perspectivas y matices diferentes en buena parte de la filosofía de los siglos XIX y XX. Una conciencia histórica y transformación que va "hasta las raíces" y representa un "cambio epocal en la experiencia de la realidad" 10 .

Hünermann ha permanecido fiel a esta perspectiva fundamental y, cuando en tiempos más próximos reflexiona sobre las características de una teología posmoderna -expresión común en el ámbito de lengua inglesa, no en el alemán-, muestra, sin explicitarlo en estos términos, que se trata de una radicalización de la conciencia de la historicidad. El autor refiere a aquellas reflexiones vinculadas a los análisis lingüísticos de Wittgenstein, las perspectivas provenientes de Heidegger, Gadamer, Ricoeur, Levinas, etc., y los proyectos deconstructivistas de Lyotard y

8 Cf. J. Costadoat, “La historia como 'lugar teológico' en la teología latinoamericana de la liberación”, en Perspectiva Teológica 47 (2015) 179-202.

9 Der Durchbruch des geschichtlichen Denkens im 19. Jahrhundert (Herder, Freiburg i.Br. 1967) 14-15.

10 Cf. "El Vaticano II como giro en la teología del siglo XX", en El Vaticano II como software, 41-70, 46. 
Derrida. Un pluralismo insuperable de mundos de la vida parece ser una característica esencial ${ }^{11}$; "no hay una perspectiva central", sino una "realidad policéntrica" en la que la vida social está "dividida en dimensiones funcionales" con sistemas y estructuras con lógicas, objetivos y métodos autónomos, aunque no autárquicos, que reclaman procesos de integración en la formación de las identidades humanas. Nos encontramos en una situación cultural diversa y con perspectivas filosóficas que incluyen "nuevas formas de pensar y de argumentar" ción a la descripción realizada por Gaudium et spes, que exigen un "cambio de la ratio fidei y del estilo de la vida cristiana" teológica transformada" a precisar ${ }^{14}$.

La historia es pensada en este contexto temático como "una idea trascendental que nos hace accesible la realidad en su conjunto y contemporáneamente nos permite abrirnos a experiencias siempre nuevas -preservándonos de estrategias de inmunización y del devenir indiferente con respecto a la experiencia-" ${ }^{\prime 15}$. Una tesis de Hünermann reside en que la fe y la teología asumieron este cambio en la comprensión de la realidad con el desarrollo de la idea de historia de la salvación. En su opinión, esta perspectiva está bien ejemplificada en la obra editorial emprendida en 1958 que vio la luz en lengua alemana en 1965, Mysterium salutis, especificada por su subtítulo: Manual de teología como bistoria de la salvación. Junto a la llamada nouvelle théologie de lengua francesa representan indicios nítidos de una toma de distancia del modelo estático y de la metodología teológica neoescolástica, que incluso habían determinado fuertemente los documentos preparatorios para el Concilio.

11 Cf. "Gestern und heute. Eine konstrastierende Relecture der Situation des Menschen in der heutigen Welt (GS 4-10)", en P. Hünermann, Das Zweite Vatikanische Konzil, 29-61, 59-60.

12 P. Hünermann, "Continuity and Discontinuity in an Epochal Transition of Faith. The Hermeneutics of Vatican II", en M. Faggioli - A. Vicini (eds.), The Legacy of Vatican II (Paulist Press, New Jersey 2015) 38-62, 40.

13 "Continuity and Discontinuity", 48. En "Geschichtliches Denken und Reform der Kirche", en Cristianesimo nella storia 34 (2013) 741-754, 743-744, habla de una "radicalización de la modernidad", que incluye una nueva experiencia del tiempo y de la finitud.

14 Cf. "Gestern und heute", 60.

15 "El Vaticano II como giro en la teología", 50. 


\section{LOS TEXTOS CONCILIARES Y SU REFERENCIA AL TIEMPO Y A LA HISTORIA}

En distintas publicaciones Hünermann muestra de qué manera y hasta qué punto el Vaticano II asumió la conciencia histórica, "la forma histórica de pensar" ${ }^{16}$. Una primera mirada se ofrece al explicitar un dato que emerge inmediatamente: "la frecuencia con que aparecen referencias a los tiempos que corren y a sus cambios" ${ }^{17}$. Esto es posible verificarlo en los más diversos documentos, comenzando por el primero, Sacrosanctum concilium (SC 1, 4), también en Lumen gentium (LG 1), Unitatis redintegratio (UR 1) y, naturalmente, en la Constitución pastoral.

Esta referencia al tiempo, aquí un segundo argumento, "concuerda con el modo de exposición de los documentos"18. Es posible verificar cómo los principales textos, de manera diversa, pero análoga, asumen el esquema histórico-salvífico, por ejemplo, para describir la revelación misma (DV), la naturaleza de la Iglesia (LG) y, particularmente, Gaudium et spes. El mismo proceso de formación de esta Constitución "muestra con claridad la transición de un tipo de reflexión teológica neoescolástica hacia una teología histórica orientada en la Biblia" ${ }^{19}$. Hay aquí una novedad cualitativa en relación a la bibliografía previa. "De los tratados eclesiológicos en uso no surgía ningún camino ya que las cuestiones características de la eclesiología siempre se habían debatido en un cuadro autorreferencial" 20 . Con estos textos los padres conciliares concretaron "un primer paso decisivo en vista de una nueva determinación de la Iglesia con respecto a la situación social existente, dando así un importante aporte para concretizar una visión histórico-salvífica de la Iglesia” ${ }^{21}$. En este sentido, la conciencia histórica asumida en los documentos del Vaticano II habría modelado el desarrollo de dos nociones teológicas clave: la revelación y la Iglesia.

\footnotetext{
16 "Perplejidad del lenguaje ante el Concilio Vaticano II?", 330.

17 "La acción de Dios en la historia. La teología como interpretatio temporis", en El Vaticano II como software, 175-216, 175.

18 "La acción de Dios en la historia", 177.

19 "Gestern und heute", 57. Cf. "El Vaticano II como giro en la teología", 62.

20 "El Vaticano II como giro en la teología", 62.

21 "El Vaticano II como giro en la teología", 65.
} 


\section{Pragmática, identidad y narRación}

Una tercera perspectiva de acceso, que profundiza el punto anterior, está dada por la explicitación de la "pragmática de naturaleza hermenéutica e histórica" del Concilio que conduce a la Iglesia "a una renovada determinación de su identidad" 22 . De allí la importancia del trabajo que realiza el autor para precisar esa pragmática: “Es posible describir la pragmática que caracteriza a un concilio constituido por más de 2.000 padres conciliares, expertos, periodistas, observadores, también por la intervención de la opinión pública, etc.?”23. Hünermann considera que dicha tarea es factible si se presta atención a los momentos decisivos y constitutivos del Vaticano II. Juan XXIII refleja una pragmática que puede ser detectada en tres conceptos: concilio pastoral, aggiornamento y nuevo Pentecostés. Ellos invitan a mirar la revelación y la Iglesia "teniendo en cuenta, por una parte, el tiempo presente y la situación actual de la humanidad y, por otra, el Evangelio, tal como queda patente en toda la gama de los diversos testimonios de la fe" 24 .

Dicha pragmática, que la mayoría conciliar hizo suya -a diferencia de los esquemas preparatorios y de la posición de la minoría-, se dedicó, con Pablo VI, a responder una pregunta peculiar del Vaticano II -diferente a la de todo concilio anterior- acerca de la identidad misma de la Iglesia: quid dicis de teipsa? ${ }^{25}$ Hünermann advierte con nitidez la novedad que está en juego en esta pregunta en relación a los concilios ecuménicos previos y también en referencia a las instituciones modernas: "Tal pragmática no fue nunca considerada para la Iglesia en su totalidad.” El hecho de que se haya concebido esta posibilidad histórica depende de la reflexión conceptual sobre "los procesos de formación de la identidad, que comienza recién en la época moderna. Pero la real plasmación de una pragmática semejante por parte de un gran organismo, como lo es la Iglesia, constituye de todas formas una novedad en el ámbito de la historia moderna de la humanidad"26.

22 "El Vaticano II como acontecimiento y la cuestión acerca de su pragmática", en El Vaticano II como software, 105-143, 116. Sobre la noción de pragmática, cf. C. Schickendantz, "Prólogo", en El Vaticano II como software, 38.

23 "El Vaticano II como acontecimiento", 114.

24 "El Vaticano II como acontecimiento", 116.

25 Expresión del cardenal L. Suenens en su discurso de diciembre de 1962. Cf. Acta Synodalia Sacrosancti Concilii Vaticani II, I/IV, 222-227, 223.

26 "El Vaticano II como acontecimiento", 116-117. 
Este modo de proceder impregna los documentos en la forma antes caracterizada: ellos constituyen unidades de tipo genético-histórico, "presentan el carácter de historias de Dios", "una narración en la cual se desarrolla la propia identidad"27. Es claro que, "quien quiere presentarse a sí mismo en su identidad, no puede hacer otra cosa que contar su historia." Las personas "dicen quiénes son contando sus historias, es decir, recordando al menos los acontecimientos constitutivos, describiendo las relaciones más importantes con las cuales ellos han constituido su propio ser" ${ }^{28}$. En este punto se insertan los análisis que Hünermann hace en referencia a dos conceptos de revelación diversos en el Vaticano I y el Vaticano II que, con alusión a Max Seckler, califica como un modelo teórico-instructivo frente a otro modelo comunicativo. El primero se expresa en definiciones dogmáticas, el segundo describe una acción comunicativa multidimensional. En el primero "reinaba la 'objetividad", en el segundo esas definiciones "no son posibles con este tipo de juego de lenguaje (Sprachspiel)"29.

\section{Pensar conjuntamente la fides QUaE y la fides QUa}

El mismo asunto es conceptualizado con otras nociones bien conocidas por la teología: la fides quae y la fides qua creditur, el contenido de la $\mathrm{fe}$ y el acto de creer, lo que se cree y la fe como actitud con la cual o por la cual esa realidad es creída. "Ambos elementos de la fe constituyen una unidad indisoluble, una identidad en realización, que se va acreditando de manera cada vez más profunda" ${ }^{30}$. Lo que caracteriza a los anteriores concilios, manifiesta el autor, es haberse dedicado a contenidos "objetivos" singulares (fides quae), por el contrario, la novedad del Vaticano II reside en que ambos aspectos son considerados "conjuntamente", es decir, "el momento de objetividad y el momento de la praxis son pensados al mismo tiempo y tematizados en su entramado recíproco" ${ }^{\text {31. Los }}$ padres conciliares no podían ya "hablar y actuar como en los tiempos de

27 "El Vaticano II como acontecimiento", 124, 126 respectivamente. Lo que estas historias ofrecen es, pues, un cuadro esencial para la valoración de cada asunto teológico e institucional.

28 "El Vaticano II como acontecimiento", 124.

29 Cf. "Continuity and Discontinuity", 53, 55.

30 P. Hünermann, Fe, tradición y teología como acontecer de habla y verdad. Dogmática fundamental (Herder, Barcelona 2006) 329.

31 "El trabajo teológico", 239. 
la Contrarreforma, en la cual todo el interés estaba fijado en diferencias en la fides quae"32. En este sentido, piensa Hünermann, es tarea de la teología posconciliar el apropiarse de esta perspectiva que, en concreto, "toma la forma de un lema: pensar conjuntamente la fides quae y la fides qua." Sucede con las palabras algo análogo a lo de las imágenes. "Dios y el misterio de la Iglesia son más grandes que todas las representaciones." En la medida en que una comunidad de creyentes se dirige a Dios mismo, a Jesucristo, las imágenes se utilizan en forma apropiada. Por tanto, solo en una pragmática adecuada las imágenes pueden desplegar su función indicativa. Lo que vale para las imágenes, argumenta Hünermann, vale igualmente para las palabras: "ellas solo pueden ser dichas verdaderamente si se utilizan de modo correcto. Esta relación articula el clásico lema de la necesaria pertenencia conjunta de fides qua creditur y fides quae creditur" ${ }^{\prime 3}$. No se trata solo del contenido, sino de factores extralingüísticos, de determinados contextos vitales y de una praxis sin los cuales dicho contenido resulta in-comprensible, in-creíble.

La tarea formulada en el "lema" implica revisar "la manera como la fides quae ha sido presentada hasta ahora", someter a una interpretación crítica a los objetos materiales de la fe, distinguiéndolos de sus representaciones condicionadas temporalmente - a menudo no reconocidas- que no se identifican con ellos. Pero, para Hünermann es claro, además, que "como consecuencia del cambio de ratio fidei el Vaticano II representa un nuevo estilo de vivir el Evangelio" 34 . En otros términos, la tarea descrita anteriormente no se presenta como necesaria solo en relación a la formulación de la fe, sino también en referencia a "la revisión crítica de las formas concretas de la vida eclesial y de la praxis eclesial", "adecuaciones institucionales para que el Evangelio pueda ser atestiguado con autenticidad" 35 . Es también este planteo, en la mente del autor, el que "lleva de manera inevitable a la cuestión de los signos de los tiempos" y que conduce a caracterizar a ellos como "elementos esenciales de una teología histórica en el tercer milenio" ${ }^{36}$.

\footnotetext{
32 "Continuity and Discontinuity", 49-50.

33 "El trabajo teológico", 221-222.

34 "Continuity and Discontinuity", 50.

35 "El trabajo teológico", 249.

36 "El trabajo teológico", 240 (cursivas mías).
} 


\section{UNA NOCIÓN MODERNA Y SECULAR DE HISTORIA}

Las consideraciones anteriores sobre identidad y narración dejan claro que en los textos del Vaticano II se presupone un obrar de Dios en la historia. Pero, ¿cómo debe pensarse y explicarse hoy dicha acción? En atención al horizonte de comprensión de los interlocutores contemporáneos la preocupación de Hünermann en este punto es doble: ofrecer un argumento teológicamente consistente y, a la vez, creíble para las personas de nuestro tiempo. Dos pasos pueden individuarse para encarrilar la respuesta a esta cuestión: una noción de historia actualizada y una explicación convincente de la acción de Dios.

Con el deseo de precisar la argumentación, Hünermann asume una definición o descripción de la noción de historia formulada "en el ámbito de la comprensión moderna y secular de la historia" de un autor que cita en más de una oportunidad en sus obras ${ }^{37}$. Richard Schaeffler afirma que una "definición nominal" de historia que se corresponda con su "uso común" puede formularse en estos términos:

"La secuencia de transformaciones de las relaciones vitales humanas -considerando como una parte esencial de esas transformaciones a las decisiones libres- y en tanto ellas son reconstruibles para nosotros mediante la interpretación de testimonios. En ella se indica el término 'secuencia' o 'sucesión' ya que los acontecimientos singulares solo tienen el carácter de históricos debido a que poseen una conexión entre ellos" ${ }^{\prime 3}$.

37 "El trabajo teológico", 243; “Geschichtliches Denken”, 751.

38 R. Schaeffler, "Geschichte, Geschichtlichkeit. I. Begriffsgeschichte. II. Philosophish", en Lexikon für Theologie und Kirche. Bd. 4 (Herder, Freiburg i.Br. $\left.{ }^{3} 1995\right)$ 553-556, 553. Este uso del concepto de historia se concreta recién a fines del siglo XVIII. La palabra griega y latina 'historia' caracterizaba originalmente toda forma de conocimiento no deducido de principios, sino a partir de la propia experiencia o de la experiencia adquiridas por otros testimonios. El contenido de ese conocimiento se calificaba como 'verdades de hecho' cuya característica distintiva era la contingencia, a diferencia de aquellos conocimientos llamados 'verdades de razón' cuya característica era el ser conceptualmente necesarios. El concepto de historia formulado en la definición nominal surge cuando se pone en discusión esta diferenciación, al advertir que también las verdades de razón están sometidas a transformaciones en las cuales se implica la libertad humana. La idea de la Ilustración como mayoría de edad de la razón ofrece los primeros indicios de esa historia de la razón. 
Están incluidas en esta definición las características básicas sin las cuales no puede hablarse de historia: (a) secuencia de sucesos o cambios en las relaciones humanas; (b) praxis humana, decisiones libres, que distinguen la historia propiamente dicha de un proceso meramente natural; (c) formación de un conjunto, a diferencia de una suma aislada y desconectada de eventos; (d) reconstruido o interpretado por testimonios, que distingue la historia stricte dicta de la pre-historia.

Por una parte, Hünermann ratifica esta cualificación de Schaeffler: "Los acontecimientos singulares adquieren su significado y su lugar solo por medio de la tensión registrada en la totalidad de los acontecimientos y en el contexto narrativo" 39 . Por otra, destaca su referencia a la teología. Mientras que la noción filosófica tematiza la historia como un conjunto de sucesos, cuyo contenido es el desarrollo de lo humano y de esta manera representa una legitimación de la modernidad, la teología desarrolla el conjunto de sucesos como una comunicación divino-humana. Esta correspondencia, argumenta Hünermann, constituyó el presupuesto para los nuevos puntos de partida que desplegó la Escuela de Tubinga en el siglo XIX y que permiten entender la historia como revelación de Dios, comprendida como la autoapertura de Dios que incluye la creación como presupuesto y que posibilita la existencia humana y el espacio de la libertad en los que se realizan las acciones que dan forma a la historia. Dei Verbum asumió esencialmente esa concepción. Una reflexión teológico-sistemática actual, piensa el autor en este contexto, debe recurrir al instrumental filosófico actual propio de los desarrollos de la fenomenología, la filosofía trascendental y la filosofía del lenguaje ${ }^{40}$.

39 "El trabajo teológico", 241.

40 Cf. P. Hünermann, "Geschichte, Geschichtlichkeit. V. In der Theologie", en Lexikon für Theologie und Kirche. Bd. 4, 559-563, 562. Hünermann no explicita una perspectiva posmoderna del concepto, que Schaeffler sí expresa en este contexto: esbozos que renuncian a una visión general de la historia. La unidad de la historia se disgrega en una multiplicidad de historias singulares que se superponen y no constituyen un conjunto con una perspectiva final común. Esta comprensión fue expresada por Arthur Danto con la fórmula: History tells stories. La cuestión filosófica-histórica se reduce aquí al problema acerca de a partir de cuáles características estructurales propias determinados sucesos vinculados se distinguen de otros eventos asociados. Cf. "Geschichte”, 555-556. 


\section{Acción de Dios en la historia en el Vaticano I y en el Vaticano II}

Acogida una descripción "moderna y secular" de historia, una reflexión a modo de contraste le ayuda al autor a precisar su posición. Pone de relieve la manera como el Vaticano I afrontó la cuestión de la acción de Dios en la historia, comparándola y diferenciándola de la tarea realizada por el Vaticano II.

En el contexto de la revelación y de la fe se afirma en el Vaticano I que a los efectos interiores del Espíritu se le agregan los milagros y las profecías como "signos de la revelación divina":

"Sin embargo, para que el obsequio de nuestra fe sea de acuerdo a la razón (cf. Rm 12, 1), quiso Dios que a los auxilios internos del Espíritu Santo se juntaran argumentos externos de su revelación, a saber, hechos divinos y, ante todo, los milagros y las profecías que, mostrando de consuno luminosamente la omnipotencia y ciencia infinita de Dios, son signos ciertísimos y acomodados a la inteligencia de todos, de la revelación divina. Por eso, tanto Moisés y los profetas, y especialmente el mismo Cristo Nuestro Señor, hicieron y pronunciaron muchos y clarísimos milagros y profecías" (DH 3009) ${ }^{41}$.

En otras palabras, los milagros y las profecías -entendida aquí la profecía como acción de predecir un acontecimiento futuro- atestiguan con seguridad las intervenciones de Dios. De esta manera, constata Hünermann, acudiendo a los milagros y a las profecías como señales inconfundibles de la acción de Dios, la historia y los hechos históricosalvíficos aparecen separados y contrapuestos. Según esta concepción Dios conduciría la historia "desde afuera", mediante una providencia que "cae del cielo", que de hecho quita consistencia a los sucesos históricos concretos. En ese esquema de pensamiento parece que se reconoce la presencia divina cuando la historia se suspende y se produce

41 Las objeciones de Hünermann a esta manera de argumentar se multiplican: "La realidad no es tan simple como para poder decir claramente lo que es "natural" y lo que es "divino". La pregunta se agudiza todavía más: ¿no hay aquí una visión mítica del mundo? ¿No se está anunciando a un Dios que, junto a las realizaciones humanas en la historia y al discurrir "natural" de las causas y efectos finitos, pone sus obras "sobrenaturales", que no se pueden ni explicar ni producir de modo natural? Finalmente, ¿es la Iglesia un signo seguro y manifiesto de credibilidad como la presenta el Vaticano I? ¿Acaso no se reconoce que existen pecados y errores en la historia de la Iglesia?" Cf. "La acción de Dios en la historia", 181. Cf. sobre la Iglesia en el Vaticano I, DH 3013. 
un suceso metahistórico, un "milagro", aunque este concepto contiene más problemas para su delimitación de lo que ordinariamente se asume. "Así pues se trata también en el concilio Vaticano I de acontecimientos histórico-salvíficos, pero 'caen' verticalmente desde arriba en la historia... profecías divinas y mensajes legitimados por testigos y por aquellos hechos milagrosos que trascienden lo natural" ${ }^{42}$. Lo que observa Hünermann aquí es "una 'reivindicación externa' de la historia por una Iglesia que reclama su legitimación” elaborada desde la escolástica barroca hasta la neoescolástica del siglo XX. Por el contrario, con la Escuela teológica de Tubinga en el siglo XIX se presenta un enfoque teológico que, por una parte, posee el tipo de definición de historia como la apuntada, por otra, "nuevamente reúne la revelación de Dios y la historia" como se refleja en la noción de revelación de Dei Verbum ${ }^{43}$.

Los presupuestos del Vaticano II orientan en una dirección diversa a la formulada por el Vaticano I: "la fe como interpretación de la historia descubre el actuar de Dios en la historia, sin negar los aspectos histórico-profanos de los acontecimientos" ${ }^{44}$. A partir de una determinada antropología, que describe adecuadamente la relación entre Dios y la creatura humana como "una relación de fundamentación, en la cual, el actuar divino fundante, constituye el obrar humano como un obrar co-respondiente (antwortendes), fundado" y conforme a la definición de historia antes apuntada, la posibilidad de hablar de una acción de Dios en la historia la ofrecen las libres decisiones de los seres humanos. "El obrar de Dios en la historia está dado en el obrar y mediante las decisiones humanas", en la conciencia humana ${ }^{45}$. La acción de Dios se manifiesta y realiza en ellas. Por tanto, si se "concibe de este modo la acción de Dios en la historia, se deben vislumbrar fenómenos en la historia que ofrezcan testimonio de ella." En este contexto se sitúa la importante iniciativa de Juan XXIII: "descubre tales fenómenos en los signos de los tiempos" 46 . En este sentido, la "historia permanece en el espacio de los signa, de los signos que -con los ojos de la fe- refieren a algo más allá

\footnotetext{
42 "La acción de Dios en la historia", 180.

43 Cf. "El trabajo teológico", 253-254 (cursiva mía); Fe, tradición y teología, 240.

44 "La acción de Dios en la historia", 208 (cursivas mías).

45 Cf. "La acción de Dios en la historia", 192-193 (cursivas mías).

46 "El trabajo teológico", 254.
} 
de ellos y que, en tanto verisimilia -verosímiles, probables-, afirman la credibilidad de la fe, sin poder borrar su ambigüedad" 47 .

\section{RENOVACIÓN DEL MÉTODO TEOLÓGICO Y RADICALIZACIÓN DE LA DIALÉCTI- CA TÓPICA}

Hünermann reconoce que después del Concilio "se ha observado repetidas veces que los padres conciliares no se dieron cuenta de haber hecho teología siguiendo un método esencialmente distinto al habitualmente utilizado en la teología de escuela." Sin embargo, considera que esta observación, que en sí misma no es irrelevante, no debe ser entendida como un reproche a ellos. "Quien se presenta a sí mismo -argumenta el autor- no reflexiona en la narración sobre los presupuestos metodológicos implícitos en su acción." De allí la importancia de la "posterior elaboración conceptual de este evento, cuando se trata de interpretar de modo metodológico y científicamente fundado los documentos conciliares" ${ }^{48}$. ¿Cómo se caracteriza esta renovación y qué se expresa con la calificación de un método "esencialmente distinto"?

El teólogo alemán coincide con el análisis de otros autores y autoras acerca de la importancia capital de la primera sesión del Concilio, menos por sus desarrollos temáticos, que por sus discusiones estratégicas y metodológicas. En esos meses de 1962, particularmente en los debates referidos al esquema sobre las fuentes de la revelación, se visibilizaron con nitidez dos formas diversas de proceder teológicamente: por una parte, una pragmática "nueva", "distinta"; "no se trataba de una pragmática teórica, sino de una pragmática global", "más que de cuestiones teológicas particulares", "de naturaleza hermenéutica e histórica al mismo tiempo", por otra, "la pragmática de los custodios de la fe", la llamada minoría conciliar, "que conocían las cuestiones, los problemas y las lagunas del sistema eclesial y teológico que ellos representaban, y se preocupaban por encontrarles solución" ${ }^{49}$.

Hünermann explicita la diferencia poniendo de relieve la diversa manera en que utilizaron la dialéctica tópica de Melchor Cano que, afirma, constituye "como el modo de elaboración del intellectus fidel"

47 "La acción de Dios en la historia", 208.

48 "El Vaticano II como acontecimiento", 126 (cursiva mía).

49 Cf. "El Vaticano II como acontecimiento", 123, 124, 116, 119 respectivamente.

50 "El Vaticano II como acontecimiento", 128. 
ría no solo se focalizó en los desarrollos magisteriales más recientes, sino que además se dejó guiar por "el principio neoescolástico, de acuerdo al cual, a partir de los textos ya definidos, se procede a una reconstrucción de la entera comprensión de la fe." Las limitaciones en esta forma de proceder son evidentes. "De esta manera, no se permite a la Escritura y a las tradiciones antiguas validarse en sí mismas como entidades autónomas, sino que se las subordina a las afirmaciones más recientes" ${ }^{51}$. En este sentido, el tipo de teología de la llamada minoría presente en el Vaticano II, conforme a los manuales neoescolásticos conocidos por ellos, conservaron el esquema metodológico de Cano comprendiéndolo "como un sistema de procesos deductivos". En este esquema la forma de la teología era pensada mediante una "metodología abstracta" como una "deducción lógica a partir de principios", de allí que ella fuera ejercitada como "una ciencia no-histórica, aunque los loci sean instancias históricas del testimonio dado de la fe" ${ }^{\text {53 }}$. Dos tareas específicas no se encuentran en el modo de argumentar "de los custodios de la fe": por una parte, no incorporan los resultados y las perspectivas de las investigaciones históricas en los loci proprii, particularmente en la consideración de la Escritura y de la tradición, por otra, no relacionan los lugares propios con los loci theologici alieni. "Para esta minoría, la cuestión era la doctrina inmutable, que luego debe ser aplicada en el plano pastoral" ${ }^{54}$.

51 "El Vaticano II como acontecimiento", 137.

52 P. Hünermann, "Criterios para la recepción del concilio Vaticano II. Hacia nuevas formas históricas de la fe y de la vida eclesial", en El Vaticano II como software, 71 104, 90.

53 Fe, tradición y teología, 224. El hecho de que Hünermann recurra en este contexto a Melchor Cano y su doctrina de los lugares teológicos tiene que ver con su propia atención a la metodología y también con un diagnóstico actual sobre la pluralidad de teologías que corre el peligro de convertir a la disciplina en "una suma azarosa" de asuntos materiales. “¿Cómo se enfrenta ese peligro?”, pregunta el autor. “¡Solo mediante una renovada afirmación de los loci theologici como puntos de referencia del trabajo teológico, como las autoridades a partir de las cuales deben normarse los argumentos de la teología!" Cf. "Nuevos loci theologici. Un aporte para la renovación metodológica de la teología”, en El Vaticano II como software, 263-291, 271. Esta opción tiene una fundamentación adecuada en otros dos argumentos, por lo menos: La dialéctica tópica de Cano otorga una estructura a la teología que influye de manera decisiva hasta la mitad del siglo XX, por una parte $\mathrm{y}$, por otra, en dicha estructura se introduce explícitamente -por primera vez- a la historia como autoridad teológica.

54 "El Vaticano II como acontecimiento", 124. 
Los padres conciliares, en su mayoría, por el contrario, "renovaron el método teológico en boga desde la época moderna y puesto a su disposición por la tradición". ${ }^{55}$ Acudieron a los loci proprii et alieni, pero lo hicieron de una nueva manera. Renovaron su tratamiento a partir de una consideración histórica de cada uno de ellos, lo cual les permitió ganar en riqueza y en complejidad, por ejemplo, en el caso de la Escritura, asumiendo -relativamente- los avances realizados por los métodos histórico-críticos y la investigación especializada. De modo análogo el tratamiento de la tradición se vio enriquecido por las nuevas investigaciones histórico-teológicas gracias, por ejemplo, al movimiento litúrgico, a la revitalización de la investigación patrística y a los estudios sobre los concilios.

Un aspecto central de la renovación metodológica residió también en una nueva forma de utilizar los loci theologici alieni. Puntos de referencia y hogar de los argumentos -loci- fueron para los padres conciliares "las grandes concepciones antropológicas, culturales, jurídico-institucionales, sociológicas y económicas que, sostenidas por un amplio consenso ético en la humanidad actual, son, por así decirlo, formaciones de la razón histórica general de la época moderna" ${ }^{56}$. Aquí se sitúa metodológicamente la tarea de interpretación de los signos de los tiempos formulada por Gaudium et spes. Desde esta perspectiva se advierte "el significado constitutivo de los observadores de las otras iglesias y, además, el significado de la opinión pública representada por los medios de comunicación" ${ }^{\prime 57}$.

En relación a la historia se visualiza una doble modificación en el tratamiento de los loci theologici: por una parte, todos los loci theologici, proprii et alieni, son abordados mediante una hermenéutica histórica, ya no más como meras proposiciones teóricas abstractas. Emerge una "visión genética de los distintos topoi" 58 . Por otra, el locus theologicus historia adquiere una nueva cualidad - una nueva autoridad- en el proceso de reflexión y argumentación teológica.

55 "El Vaticano II como acontecimiento", 138.

56 "El Vaticano II como acontecimiento", 138.

57 "El Vaticano II como acontecimiento", 131 (cursiva mía).

58 Fe, tradición y teología, 239. Cf. Fe, tradición y teología, 281. 
Hünermann destaca un paso más en referencia al modo de hacer teología: "El Concilio radicalizó decididamente este método" 59 , no solo lo renovó. Advierte que "ni en Melchor Cano ni en la tradición seguida hasta entonces este método había sido aplicado a la autocomprensión de la Iglesia en su conjunto y a la comprensión de la revelación en cuanto tal." En ambos casos "se encontraban en primer plano cuestiones teológicas singulares; sobre ellas versaban las discusiones respectivas". Además, también en la "modalidad de su realización los padres conciliares radicalizaron la dialéctica tópica de la fe", observa. "Existe una diferencia cualitativa entre el tratamiento de esta temática por parte de teólogos/as y la concreción real de tal proceso por parte de obispos, que representan a la Iglesia." A diferencia de la tarea de los teólogos y de un obispo particular, "el episcopado mundial reunido en concilio representa a la Iglesia en una forma de expresión del todo diversa" ${ }^{\prime 0}$. En la medida en que corresponde a un concilio una competencia directiva universal, la dialéctica tópica de la fe se presenta en este caso como un instrumento al servicio del proceso de conducción de la Iglesia.

Esta dialéctica tópica -renovada y radicalizada- constituye el movimiento de fondo del Concilio, piensa Hünermann, "ese movimiento unitario que ha vinculado las innumerables actividades singulares y las ha insertado en un flujo que ha producido, como fruto y resultado, la nueva visión de la Iglesia y de la revelación que ha encontrado su expresión en los textos del Concilio". En esta pragmática o forma de proceder es posible encontrar, por una parte, el "inicio de un nuevo tipo de teología en la Iglesia postridentina", por otra, "un nuevo tipo de dirección responsable de la Iglesia" ${ }^{61}$.

\section{LOS SIGNOS DE LOS TIEMPOS: "FUERTES LÍNEAS DE CONSENSO"}

Como se refirió en la introducción, Hünermann constata un problema que también otros destacan: las dificultades y las perplejidades acerca de la "determinación conceptual" y de la elaboración de "criterios claros y universalmente válidos para la determinación" de los signos de los tiempos. No obstante, el autor piensa que es posible distinguir "fuertes líneas

\footnotetext{
59 "El Vaticano II como acontecimiento", 132 (cursiva mía).

60 "El Vaticano II como acontecimiento", 133.

61 "El Vaticano II como acontecimiento", 139, 136.
} 
de consenso" en la teología actual ${ }^{62}$. Existen dos niveles en la consideración de dichos signos que es necesario distinguir, pero que no es posible separar. El primero, presta atención a la realidad histórica concreta de los eventos y su significación ético-filosófica. El segundo, interpreta dichos eventos como fenómenos teológicos. En esos niveles se formulan criterios en un orden que no implica una mayor relevancia.

\subsection{Realidades históricas y significación ético-filosófica}

(a) Conforme al significado presentado en el Concilio al momento de la inclusión de la noción en el debate en el aula conciliar, los signos de los tiempos son concebidos de una manera genérica como acontecimientos que distinguen un período de tiempo: "Son aquellos fenómenos que, por su universalidad y su gran frecuencia, caracterizan a una época y mediante los cuales se expresan las necesidades y las aspiraciones (besoins et aspirations) de la humanidad actual"63.

(b) Estas necesidades y aspiraciones $-\mathrm{O}$ necesidades y anhelos- no son exclusivas de individuos o pequeños grupos, sino que atañen a la bumanidad en su conjunto.

(c) Su identificación es fruto de un consenso moral universal.

(d) Constituyen un fenómeno moral, no un suceso meramente natural. Son pensados como el resultado de acciones humanas libres, en ellas y mediante ellas.

(e) Como verdaderos signos -fenómenos morales de significado sobresaliente- se pueden distinguir adecuadamente gracias a su carácter ejemplar, significante y decisivo para muchos, puesto que se vincula con ellos una comprensión esencial de las realidades humanas, significativa y moralmente incuestionable. Se distinguen de los fenómenos morales sin-

${ }^{62}$ Cf. "El trabajo teológico", 242. Cf. E. SILVA, "Criterios de discernimiento. para una teología de los signos de los tiempos latinoamericanos", en V. Azcuy - C. Schickendantz - E. Silva (eds.), Teología de los signos de los tiempos latinoamericanos. Horizontes, criterios y métodos (Ed. Universidad A. Hurtado, Santiago 2013) 173-208.

63 "La acción de Dios en la historia", 198. Hünermann se sirve aquí del importante trabajo de G. Turbanti, Un concilio per un mondo moderno. La redazione della costituziione pastorale 'Gaudium et spes' del Vaticano II (Il Mulino, Bologna 2000) 374, nota 183. Cf. C. Schickendantz, "Una elipse con dos focos. Hacia un nuevo método teológico a partir de Gaudium et spes", en Teología 110 (2013) 85-109, 100. 
gulares. 'Verdaderos 'acontecimientos' producen estructuras de larga duración"

(f) Además, es importante para el carácter de signo que lo ocurrido se vincule con una experiencia de revelación o descubrimiento y, con ella, aflore el carácter temporal de ese fenómeno en su valor histórico de novedad.

(g) Experiencias positivas y también negativas que, por contraste o reacción, suscitan un movimiento en favor de la dignidad y los derechos humanos. Dichos fenómenos pueden ser de naturaleza muy variada: grandes catástrofes humanas, situaciones de injusticia o peligros masivos pueden ser el inicio de innovadores procesos de formación de la conciencia ${ }^{65}$.

(h) La historia humana es en sí misma una historia de ambivalencias. "Es imposible una justificación de la histórica fáctica desde la acción, las obras y los propósitos humanos. El sentido de la historia humana no surge a partir de la historia misma"

\subsection{Como fenómenos teológicos}

Sobre estos presupuestos se edifica la mirada teológica, mediante la cual "sucesos históricos llegan a ser signos de los tiempos mesiánicos" ${ }^{67}$. La fe es respuesta al Dios que se revela, que se comunica a sí mismo bajo y mediante acontecimientos históricos. Los creyentes reciben sus vidas, los acontecimientos de la mano de Dios. Y esto significa, al mismo tiempo, que ven y juzgan desde la perspectiva de la fe. "La fe cristiana lleva consigo una visión radicalmente histórica de la vida que está entretejida por el obrar de Dios" ${ }^{98}$. Esta mirada o perspectiva de la fe no quita densidad o autonomía a los sucesos históricos concretos: "la fe como interpretación de la historia descubre el actuar de Dios en la bistoria, sin negar los aspectos histórico-profanos de los acontecimientos”. En este

64 Cf. "La acción de Dios en la historia", 197: "Como acontecimientos no se entienden aquí simplemente los hechos naturales, sino aquellos sucesos mediante los cuales se transforman las relaciones, no solo fácticamente, sino también en la conciencia de los seres humanos."

65 Cf. "La acción de Dios en la historia", 201.

66 "El trabajo teológico", 246.

67 "La acción de Dios en la historia", 202.

68 "La acción de Dios en la historia", 206. 
sentido, la historia, comprendida en toda su singularidad y complejidad, "permanece en el espacio de los signa, de los signos que -con los ojos de la fe- refieren a algo más allá de ellos" ${ }^{\circ}$.

(a) Donde se hacen experiencias en favor de la humanidad que impregnan una época y, al mismo tiempo, se reconoce una responsabilidad moral y se suscita un movimiento histórico en favor de ese compromiso moral "allí se afirma, para los creyentes y para la Iglesia, una presencia oculta del Dios que se revela, una acción de su Espíritu en la historia"70. Se trata de "un proceso que se inscribe en la revelación de Dios, en el Evangelio, en tanto que en él se promete a la humanidad que, a pesar de su pecado, Dios la conducirá a través de la historia hacia la realización de su ser mediante su autocomunicación"71.

(b) Como no se refiere a una intervención de Dios realizada desde fuera, ab extra -en los términos del Vaticano I- la historia humana permanece como una historia de ambivalencias. De allí que los signos de los tiempos no constituyen "algo evidente; deben ser descubiertos y leídos en los múltiples y complejos sucesos humanos." Dicho proceso de discernimiento exige, por una parte, un análisis pormenorizado del fenómeno mismo con la ayuda de las más diversas perspectivas y ciencias, por otra, implica el dejarse guiar por los criterios éticos antes formulados y, particularmente, por criterios teológicos. Supone "una interpretatio christiana del proceso que está a la vista" ${ }^{\prime 2}$.

(c) La interpretación creyente requiere para su justificación teológica del discernimiento acerca de cómo los hechos en cuestión "se corresponden con el espíritu del Evangelio"; cómo las raíces de esa experiencia de humanidad "están dadas en la tradición de la fe cristiana"; de qué manera la afirmación de ese hecho como un signo de los tiempos se inscribe en las formas de vida y en la praxis de la Iglesia guiadas por el Evangelio ${ }^{73}$.

(d) Los padres conciliares acudieron a los signos de los tiempos "apoyándose en la doctrina de Jesús sobre los signos de los tiempos." Jesús se refiere a los signos mesiánicos que han sido anunciados por los profetas

\footnotetext{
69 "La acción de Dios en la historia", 208 (cursiva original).

70 "El trabajo teológico", 247 (cursiva mía).

71 "El trabajo teológico", 247.

72 "El trabajo teológico", 248.

73 Cf. "El trabajo teológico", 248.
} 
y deben ser realizados por Él, por ejemplo, en su prédica en Nazaret (Lc 2, 34). "En los signos mesiánicos, que Jesús realiza de obra y palabra, se anuncia la superación del desorden y del mal -frutos de la lejanía de Dios- que afectan las relaciones humanas." También se anuncia el reino de paz que Dios desea para los seres humanos, así como la presencia plena de las bendiciones de Dios y de los efectos de su Espíritu. "En él mismo, como el signo mesiánico, se manifiesta -en tanto asume la Pasión dispuesta por los seres humanos- el "rechazo" (Mt 21,42) del amor infinito del Hijo, que es la revelación, la irradiación del amor del Padre" ${ }^{74}$.

(e) Desde esta perspectiva cristológica -esencial y determinante- se percibe más profundamente la mirada teológica sobre las experiencias negativas ya referidas. Es necesario, sin embargo, que estos fenómenos sean reconocidos y leídos en el espíritu del Evangelio. Entonces se muestra "una visión de las relaciones vitales queridas originariamente por Dios. Así brilla algo del reino de paz definitivo al que apunta Dios. Pero justamente aquí muestra Dios - muchas veces sub contrario- su presencia operante en la historia, el obrar de su Espíritu"75. En los signos se "desvela así históricamente algo de la 'esencia' o de la 'naturaleza" del ser humano ${ }^{76}$.

(f) Los creyentes reconocen en los signos discernidos los efectos del Espíritu, la presencia de Dios. De este modo, estos signos mesiánicos "son momentos que pertenecen constitutivamente al Evangelio y a su prédica en ese tiempo. Son acontecimientos, tendencias y procesos de concientización a los que la Iglesia y los creyentes deben atender y, purificados de posibles interferencias ideológicas, los deben afirmar e integrar en la figura histórica de la vida de fe." La fe cristiana llega a ser actual y viva -precisamente- "mediante tal 'in-miscuirse' temporal"'77.

(g) El sujeto del discernimiento es todo el pueblo de Dios. En ese marco amplio, resulta fundamental a los ojos de Hünermann la tarea de teólo-

\footnotetext{
74 "La acción de Dios en la historia", 200-201. Hünermann es consciente del ambiente del Vaticano II en el que surge la categoría signos de los tiempos; en parte un contexto escatológico, en parte un contexto sociológico.

75 "La acción de Dios en la historia", 202.

76 Cf. Fe, tradición y teología, 309 nota 493.

77 "La acción de Dios en la historia", 206-207 (cursivas mías).
} 
gos y teólogas -más precisamente la comunidad científica teológica- ${ }^{78}$ y, particularmente, el discernimiento de aquellas personas "que manifiestan una especial sensibilidad por los signos de los tiempos", aquellos espacios en los cuales se "manifiestan más tempranamente procesos que conducen al reconocimiento" de dichos signos. En este contexto y sin ánimo exhaustivo el autor recuerda dos ámbitos: grupos carismáticos -en un sentido amplio- y el sensus fidelium del pueblo de Dios ${ }^{79}$.

(h) Solo en la praxis de la Iglesia, que asume el signo identificado, este adquiere "su realidad plena". De representar una señal o indicio pasa a ser "un signo eficaz de la acción histórica de Dios. La actuación de Dios se hace presente solo en la praxis testimonial" de los seres humanos ${ }^{80}$. La implícita alusión sacramental - un signo eficaz- y la importancia del testimonio - conforme a la noción de historia utilizada- están bien destacadas. De allí la significación de la reflexión sobre las nociones de testigo y testimonio para una teología de los signos de los tiempos ${ }^{81}$. La experiencia del testigo -individual o comunitaria- no es por sí misma un signo de los tiempos, pero sí un constitutivo esencial, imprescindible, en la emergencia de un signo. Por otra parte, el argumento formulado -solo en la praxis de la Iglesia el signo adquiere "su realidad plena"- supone una adecuada concepción de la Iglesia y su catolicidad "como a priori teológico de la fe", en el sentido en que "en ella está dada la pragmática en la que el cristiano puede realizar la fe en el Dios trino que se revela" ${ }^{\text {. }}$

(i) La Iglesia, caracterizada como un pueblo de Dios mesiánico, está esencialmente comprometida al llevar el mensaje del Evangelio "en discernir los signos de los tiempos como signos mesiánicos y, en su praxis, dejarse conducir por ellos." De esta manera, "atestigua que 'el Reino de Dios está cerca’ y se mueve al encuentro de la acción de Dios en la historia. A partir de signos de los tiempos mesiánicos cobran sentido en la fe los

78 Un aspecto repetido en Hünermann en relación a la teología como una ciencia acorde a la época reside en su esencial referencia a una comunidad científica. Este argumento debe incluirse también aquí.

79 Cf. "El trabajo teológico", 250.

80 "El trabajo teológico", 248 (cursivas mías).

81 Cf. S. Kaufmann, "Testimonio, atestación, testigo. Reflexiones a partir de Paul Ricoeur", en V. Azcuy - C. Schickendantz - E. Silva, Teología de los signos de los tiempos latinoamericanos, 317-354.

82 “Perplejidad del lenguaje ante el Concilio Vaticano II?", 333. 
acontecimientos y la historia cotidiana" ${ }^{83}$. Los signos de los tiempos cumplen la función de guiar a la Iglesia por los nuevos caminos y, en este movimiento, ella encuentra al mismo Dios que, mediante el suceso histórico, sale a su encuentro.

(j) De este reconocimiento se siguen diversos compromisos y tareas para los creyentes, algunos de los cuales el autor explicita en este contexto. Implica, ante todo, la solidaridad de la Iglesia con los movimientos de humanización en la historia y con los grupos humanos particularmente afectados en sus derechos. En relación al trabajo teológico es posible destacar dos desafíos. La conceptualización de las verdades de la fe siempre está vinculada a horizontes de comprensión y representaciones temporales. Los signos de los tiempos son ayudas imprescindibles para la teología en orden a "revisar la manera como la fides quae ha sido presentada hasta ahora, es decir, para someter a una revisión crítica la manera de representación y características de la objiecta materialia fidei", para distinguir y eventualmente eliminar representaciones inadecuadas no reconocidas. En otras palabras, la fe que interpreta los acontecimientos históricos es ella misma reinterpretada en un círculo hermenéutico inacabable. Una tarea análoga se plantea a la teología, precisamente, para la revisión crítica de las formas concretas de la vida y de la praxis eclesial. Los signos de los tiempos exigen nuevos acentos y adecuaciones institucionales para que el Evangelio pueda ser atestiguado con autenticidad ${ }^{84}$. Ellos "confrontan a la Iglesia con su propio estado", descubren sus deficiencias y culpas que "se hallan en contradicción con la esencia de la Iglesia y con los rasgos fundamentales de la convivencia humana" $"$.

(k) Last but not least. En el contexto de revisión crítica de los contenidos de la fe recién aludida y en referencia al proceso de aprendizaje que la Iglesia realiza en orden a entender mejor su propio mensaje y sus propias formas de vida, Hünermann formula esta frase: "Es un acontecer de la "teología negativa" ${ }^{\prime 6}$. El autor explicita allí una referencia al "misterio de Dios" mismo, que mediante este proceso de purificación -distinguiéndolo de determinadas representaciones culturalmente condicionadas- aparece como "más grande" de lo que dichas represen-

\footnotetext{
83 "La acción de Dios en la historia", 203.

84 Cf. "El trabajo teológico", 249.

85 Fe, tradición y teología, 310.

86 "El trabajo teológico", 260 nota 49.
} 
taciones podían hacerlo comprensible. En otras palabras, un signo de los tiempos ayuda a comprender mejor la imagen de Dios, su peculiar trascendencia y cercanía. Dios se dice en los signos mesiánicos. Dice quién es, dice quién no es. Se autocomunica. Un fenómeno de revelación. Si en los signos se desvela históricamente quién es el ser humano -como se destacó más arriba-, también aparece quién es Dios; hay en ellos "una presencia oculta del Dios que se revela" Auschwitz o en catástrofes semejantes, por ejemplo, Él es "el Dios de los prisioneros de los campos de concentración"; alli "se vislumbra que Dios se identifica -en Cristo- con los hombres y mujeres de los campos de concentración, con los que sufren, los torturados, los muertos en las cámaras de gas", así como "en el Antiguo Testamento Dios es llamado padre de las viudas y de los huérfanos" $" 88$.

REFLEXIONES FINALES - ¿UNA AMPLIACión DE LA NOCIÓN ANÁlOGA DE REVELACIÓN?

La consideración sobre el misterio de Dios referida alude a una idea que aparece de múltiples formas en estas páginas: la acción de Dios en la historia no es solo un hecho del pasado. El Espíritu del Resucitado actúa hoy en y mediante las acciones humanas. "Solo descubriendo los signos de los tiempos en los cuales Dios obra aquí y ahora en la historia secular, puede ser creída la revelación como revelación de Dios. Solo de este modo se puede evitar que la revelación sea interpretada como una visión del mundo pasada, que solo se da en la intimidad de la fe" ${ }^{89}$. Se expresa así una perspectiva que Hünermann no tematiza exactamente con estas palabras: con la asunción de la conciencia histórica en el Vaticano II se materializa -más o menos explícitamente y de una forma inicial- una cierta ampliación de la noción de revelación. Es en estos términos, en mi opinión, la idea de fondo que está en juego en el concepto simbólico signos de los tiempos y que necesita ser precisada.

La teología de los signos de los tiempos representa un momento de renovación de la metodología teológica supuesto que ella se entienda de una determinada manera. Debe explicitarse que esta teología no solo añade un tema más, un ulterior objeto material de tratamiento, o que

\footnotetext{
87 "El trabajo teológico", 247.

88 Cf. "La acción de Dios en la historia”, 201.

89 "La acción de Dios en la historia", 192 (cursivas mías).
} 
solo contextualiza "doctrinas elaboradas de antemano", parafraseando a Y. Congar, sin valorar adecuadamente la "importancia enorme para la epistemología teológica" que tiene esta "forma relativamente nueva de teología" -inductiva y concreta-inaugurada oficialmente por Gaudium et spes $^{90}$. La "asociación aparentemente ilícita entre principios y datos empíricos" modifica la estructura del pensar teológico, su forma de proceder y de argumentar, en la medida en que reconoce una nueva cualidad, no explicitada de esta manera antes, a una de las autoridades a partir de las cuales se piensa teológicamente. Se trata de una transformación en la naturaleza misma del intellectus fidei, en la perspectiva formal de la teología, en la autoridad que posee una de las fuentes del conocimiento teológico, una de las instancias de testimonio de la Palabra de Dios: los acontecimientos históricos. El procedimiento interpretativo que en un suceso histórico y político determinado acontecido en el antiguo Egipto -un hecho puntual de la historia secular- permitió discernir en aquella liberación de la esclavitud el peculiar paso de Dios por la historia en hechos y palabras no ha caducado.

Aunque no arriba a la misma conclusión, Christoph Böttigheimer -en su texto de teología fundamental- pone los presupuestos para una consideración semejante. Afirma que "Dios no deja de revelarse", a la "esencia de Dios pertenece el revelarse". Junto a la fase de la revelación que en Jesucristo y su Espíritu ha llegado a su plenitud insuperable y normativa en el tiempo bíblico y con la muerte del último apóstol, reconoce a la "revelación privada" que le es concedida a alguien "en el tiempo posterior a la muerte del último apóstol" y que, a diferencia de la revelación pública, "no pertenece a la fe cristiana general vinculante para todos" $"$. Argumenta que la enseñanza de que en Jesucristo la revelación ha llegado a su plenitud no significa que "de allí en adelante Dios callaría y su acción salvífica tendría un fin". Dios continúa hablando a los seres humanos en la "transmisión de la revelación divina (DV 5-10)", que excluye una ulterior revelación publica de Dios en los términos expuestos. Estas justas y clásicas distinciones -que ofrecen una noción de revelación análoga, "pública" y "privada"- necesitan ser recomprendidas de modo de no caer en la situación advertida por Hünermann: que

90 Cf. Y. Congar y otros, La respuesta de los teólogos (C. Lohlé, Buenos Aires 1970) 11-18, 14.

91 Lehrbuch der Fundamentaltheologie. Die Rationaltät der Gottes-, Offenbarungs- und Kirchenfrage (Herder, Freiburg i.Br. $\left.{ }^{2} 2012\right)$ 155, 478. 
"la revelación sea interpretada como una visión del mundo pasada, que solo se da en la intimidad de la fe."

Esta consideración deja abierta la pregunta acerca de qué tipo de testimonio de revelación, qué clase de locus theologicus -en los términos de la estructura metodológica de Cano- constituye un acontecimiento histórico en el que se discierne la presencia actual de Dios y la acción del Espíritu. La cuestión podría, entonces, formularse en estos términos: ¿podría -o, más bien, debería- decirse que un locus theologicus alienus -un suceso histórico determinado- puede devenir un locus theologicus proprius -un momento de revelación-gracias a un proceso de discernimiento que advierta en él una peculiar instancia de testimonio de la Palabra? En este sentido, existirían acontecimientos históricos que pertenecen al primer tipo de autoridad, "ajeno", y otros, al ámbito "propio"92. Una distinción parece importante aquí. Un lugar hermenéutico, de suyo, no es nunca normativo para el pensar creyente. Un lugar hermenéutico -punto de partida esencial de toda teología contextual-puede llegar a ser un lugar teológico propio gracias a un proceso de discernimiento que descubra en una situación histórico-concreta un carácter de instancia de testimonio de la Palabra de Dios. De este modo un acontecimiento o experiencia adquiere una autoridad teológica que no puede ser obviada, ingresa como un instrumento peculiar a una orquesta diferenciada en donde resuena la Palabra de Dios, la sinfonía de la fe ${ }^{93}$.

La analogía con la revelación "privada" puede ser iluminadora. Vincula en la fe a quien se dirige, como argumenta H. U. von Balthasar siguiendo a Tomás de Aquino y Juan de Lugo:

"La opinión más común ya enseña que toda revelación suficientemente propuesta pertenece al objeto formal de nuestra fe, ya sea privada o públicamente propuesta por la Iglesia; pues, aunque los fieles todos no estén obligados a creer la privada, aquel a quien se ha hecho y propuesto

92 La hipótesis formulada no debe opacar otro aspecto: los acontecimientos históricos deben permanecer como locus alienus -aunque en un sentido cualitativamente diverso al pensado por Cano-, porque la fe y la teología están siempre referidas a esa alteridad.

93 C. Schickendantz, "Autoridad teológica de los acontecimientos históricos", 171, 177. Aunque Hünermann no se expresa exactamente en estos términos, sus ideas ya citadas se mueven en esta dirección. En conversación personal con él, en marzo de 2016, me ha confirmado que, en su opinión, debe hablarse de "revelación" en el sentido formulado en la hipótesis. 
suficientemente está obligado a creerla con el mismo hábito de la fe que los otros misterios de fe" ${ }^{\prime 94}$.

Una comunidad que discierne la voz de Dios en un hecho histórico concreto, ¿no está ella requerida a escucharla -análogamente- en un movimiento de fe? Se trataría de un fenómeno de revelación o de actualización de la única revelación. Son necesarias ulteriores especificaciones, pero es suficiente aquí la indicación.

Ahora bien, ¿por qué no es secundaria la hipótesis de reconocer a la historia como un posible locus theologicus proprius, como posible espacio de revelación? Para advertir con claridad el cambio que se ha producido en esa "asociación aparentemente ilícita" es necesaria una clarificación conceptual. Precisamente en tiempos de transformaciones veloces y profundas en una iglesia crecientemente plural y mundial son necesarias reflexiones fundamentales acerca de cómo pensar y argumentar teológicamente de una manera adecuada. Es análoga a la situación que impulsó a Cano a recoger la tradición metodológica, reformularla y enriquecerla con nuevas perspectivas reflexionando en cómo hacer teología correctamente en un momento histórico determinado. De allí que no sea suficiente conformarse con las innumerables afirmaciones genéricas de teólogos y teólogas de las más diversas corrientes y regiones acerca de que "Dios sigue hablando en la historia". La pregunta es cómo dicha afirmación -y otras análogas- se traducen en una metodología teológica satisfactoria. Es necesaria una "epistemología teológica transformada" que haga frente a las perplejidades, profundas y repetidas, sobre el significado del progreso acontecido germinalmente en Gaudium et spes, a la "asociación en apariencia metodológicamente ilícita entre principios y datos empíricos". La propuesta formulada -inicial e hipotética- enfrenta la cuestión abierta que constata Kasper al inicio de esta contribución: "permanece sin aclarar cómo se determinan y ordenan metodológica y teológicamente los signos de los tiempos." Aquí no podría hablarse ya de mera yuxtaposición o paralelismo entre realidad del tiempo y realidad de Dios, entre datos empíricos y principios teológicos.

94 "Lettera di saludo ai confratelli", en E. Guerriero, Hans Urs von Balthasar (Ed. Paoline, Roma 1991) 371-377, 373: "Sententía cornmunior iam docet, omnem revelationem sufficienter propositam pertinere ad objectum fórmale fidei nostrae, sive privata sit, sive publica ab Ecclesía proposita; nam licet privatam non teneantur fideles omnes communiter credere, tenetur tamen credere ille, cui fit et sufficienter proponitur, eodem habitu fidei quo credit et alia fidei mysteria". 